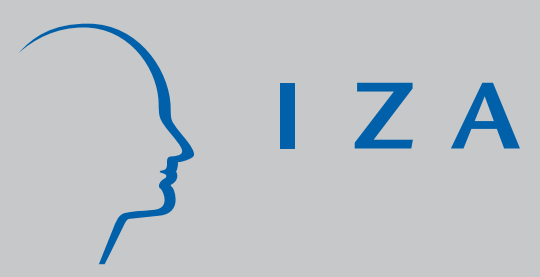

IZA DP No. 625

Endogenous Wage and Capital Dispersion, On-the-J ob Search and the Matching Technology

Fernando Galindo-Rueda

November 2002 


\title{
Endogenous Wage and Capital Dispersion, On-the-Job Search and the Matching Technology
}

\author{
Fernando Galindo-Rueda \\ University College London, London School of Economics \\ and IZA Bonn
}

\section{Discussion Paper No. 625 \\ November 2002}

\author{
IZA \\ P.O. Box 7240 \\ D-53072 Bonn \\ Germany \\ Tel.: +49-228-3894-0 \\ Fax: +49-228-3894-210 \\ Email: iza@iza.org
}

This Discussion Paper is issued within the framework of IZA's research area Welfare State and Labor Market. Any opinions expressed here are those of the author(s) and not those of the institute. Research disseminated by IZA may include views on policy, but the institute itself takes no institutional policy positions.

The Institute for the Study of Labor (IZA) in Bonn is a local and virtual international research center and a place of communication between science, politics and business. IZA is an independent, nonprofit limited liability company (Gesellschaft mit beschränkter Haftung) supported by the Deutsche Post AG. The center is associated with the University of Bonn and offers a stimulating research environment through its research networks, research support, and visitors and doctoral programs. IZA engages in (i) original and internationally competitive research in all fields of labor economics, (ii) development of policy concepts, and (iii) dissemination of research results and concepts to the interested public. The current research program deals with (1) mobility and flexibility of labor, (2) internationalization of labor markets, (3) welfare state and labor market, (4) labor markets in transition countries, (5) the future of labor, (6) evaluation of labor market policies and projects and (7) general labor economics.

IZA Discussion Papers often represent preliminary work and are circulated to encourage discussion. Citation of such a paper should account for its provisional character. A revised version may be available on the IZA website (www.iza.org) or directly from the author. 
IZA Discussion Paper No. 625

November 2002

\section{ABSTRACT \\ Endogenous Wage and Capital Dispersion, On-the-Job Search and the Matching Technology*}

This paper presents a new model of endogenous wage and capital dispersion where heterogeneity is driven by entrepreneurial incentives to pay higher wages in order to attract and retain workers. The main contribution of this model is to provide a framework with microeconomic foundations that give rise to matching frictions, which can be used to understand the dynamic features of job-worker flows, wage dispersion and mobility as well as search on the job. The basic model is also extended to endogenise firms' optimal investment in job-specific capital and search efforts undertaken by both employed and unemployed individuals. The empirical implications of this model are compared to those of the apparently more tractable and indeed, more frequently used aggregate matching technology. Existing differences turn out to be crucial for the empirical identification of the wage offer distribution and may also bias subsequent inferences about underlying search cost parameters.

JEL Classification: J39, J41, J64

Keywords: matching technology, wage posting, on-the-job search, micro-foundations, endogenous wage and capital distributions, empirical identification

Fernando Galindo-Rueda

Centre for Economic Performance

London School of Economics

Houghton Street

WC2A 2AE London

United Kingdom

Tel.: +44 2079556974

Email: f.galindo-rueda@lse.ac.uk

${ }^{*}$ First version: May 2001. Comments and suggestions from Alan Manning, Chris Pissarides, Nicola Pavoni and Gianlucca Violante, as well as participants at seminars in UCL, the IZA Summer School and the CEP Stoke Rochford Conference are gratefully acknowledged. The usual disclaimer applies. 


\section{Introduction}

Stigler's (1961) seminal paper set one of the first theoretical foundations that attempted to explain the ubiquitously observed dispersion of prices for apparently homogeneous goods. This dispersion was attributed to a process of endogenous differentiation consistent with the optimising behaviour of economic agents. This departure from the conventional setting where the 'law of one price' prevails stems from the frictions, information limits and other transaction costs that prevent allocations that would have taken place with a Walrasian-like auctioneer. In this world, a seller's concern is not only the price at which a good can be sold, but also the likelihood of this transaction actually taking place or the waiting period until it is effective. Traders rarely have a full knowledge of all the available offers and, even if they do, monetary or time constraints may make it infeasible or undesirable for them to trade simultaneously with everyone. Competition in a world where frictions are present will often lead sellers to commit to lower prices or buyers to accept higher prices than they would do otherwise. An optimal pricing strategy will thus involve the attempt to strike the right balance between conflicting objectives, given the other agents' own pricing choices.

The labour market is often presented as an example of a market where such restrictions are commonplace. In fact, firms which are apparently similar do make rather distinct offers for workers with apparently identical productivity. It has been suggested that unobservable characteristics can account for a large share of the existing wage heterogeneity and, in particular, recent increases in wage inequality in the United States and in the United Kingdom, as documented by Juhn, Murphy and Pierce (1993), Murphy and Welch (1992), Katz and Autor (1999) and Gosling, Machin and Meghir (2000). However, attributing the entire extent of earnings inequality amongst observationally equivalent individuals to characteristics which are unobserved to the econometrician is certainly an unsatisfactory explanation for such a widespread phenomenon. This approach is also likely to neglect the systematic nature of observed price heterogeneity within markets, which is often the outcome of rational differentiation behaviour of ex ante identical agents. For example, in the context of the labour market, Holzer, Katz and Krueger (1991) find that high wages attract significantly more applicants. This evidence suggests that entrepreneurs may trade off this positive recruitment effect against the negative impact of higher wages on profits.

This paper reflects on the rationale for endogenous wage dispersion in a labour market where employed individuals are not forced to give up on better opportunities that may eventually arise. This is known as the 'on-the-job search' assumption. Incentives to offer wages higher than some minimum value will exist because firms can substantially increase the likelihood of receiving applications and, simultaneously, reduce the probability that incumbent 
employees, (whose hiring process has been costly for the firm) find better offers and decide to quit. Therefore, larger wages are not necessarily bad news for a firm. There is substantial evidence suggesting that search while employed is an empirically important phenomenon. Galt (2001) shows that almost 15 percent of Canadian workers are actively seeking new jobs, and a much higher percentage can be described as having 'their eyes open' for new opportunities or offers. Furthermore, evidence from worker flows seems to confirm this pattern. Fallick and Fleischman (2001) show that the volume of job-to-job transitions is of the same order of magnitude as the job-to-unemployment transitions. Anderson and Burgess (2000) draw attention to the importance of job search incentives for employed individuals and their effects on estimated matching functions.

Models where higher wages increase a firm's idiosyncratic probability to be matched to a worker have been analysed by Burdett and Judd (1983), Burdett and Mortensen (1998) and Mortensen $(1990,1998)$. The latter incorporates this wage posting approach to search equilibria as developed by Pissarides $(1990,1994)$ and Mortensen and Pissarides (1994). This approach is based on an aggregate matching function without specific micro-foundations and set in continuous time. It is very convenient because it allows modelling the arrival rate of offers for searching agents as a function of the relative size of job offers to searching individuals. Nevertheless, it implies that matching is uniform across the distribution of offers, and then it is up to the worker to decide whether to take the job or not. In practice, some jobs will receive more applications than others, and it can not be guaranteed that following matching, a job application will be successful.

The distinctive methodological feature of this research is the departure from the uniform matching assumption in the on-the-job search environment of Mortensen (1998). Instead, it adopts the alternative specification of an urn-ball statistical model to generate the frictions that are missing in the Walrasian-auctioneer benchmark. By not allowing all agents to trade simultaneously with each other, a trade-off in the choice of wages by each firm is possible. This trade-off is not resolved in a common single best possible choice as in other typical maximisation problems because a firm's optimal decision depends on what the others do and there are incentives for firms to differentiate themselves from each other.

This type of matching technology is also used by Acemoglu and Shimer (2000), who investigate the phenomenon of wage dispersion from a different perspective. In their model, search activities by unemployed individuals are endogenised in the sense that they can choose how many offers to sample at a given cost. ${ }^{1}$ When some workers sample two or more offers,

\footnotetext{
${ }^{1}$ This model is a generalisation of that by Burdett and Judd (1983). Other contributions which make use of the urn-ball model to assess wage posting are Lang (1991), Montgomery (1991) and Peters (1991). See the survey by Petrongolo and Pissarides (2000) for a comparison of alternative matching function specifications.
} 
incentives for wage dispersion appear because larger wages can attract applications from workers who sample more than one offer. Such a model has a very static focus (even though they consider a dynamic version in steady state) because on-the-job search is not allowed. Thus, career progression would play no role in shaping inequality.

In contrast, my model restricts the maximum number of offers that any individual can sample per period to one. ${ }^{2}$ Wage dispersion arises for similar reasons: higher wages serve the purpose of reducing the period in which capital remains idle - with the subsequent savings in terms of the investment opportunity cost. More applications imply anticipation of the date production begins and delaying the day it endogenously might come to an end because the worker finds a better offer. In contrast to Acemoglu and Shimer (2000), direct competition between firms (i.e.comparison of two offers) is restricted to happen between vacant and filled jobs. The only interference among vacant firms operates in the form of a congestion externality, wherein a larger number of vacancies reduces the expected number of contacts made with workers.

On-the-job search and multiple sampling of job offers are alternative mechanisms aimed at resolving the problem known as the 'Diamond paradox'. ${ }^{3}$ Diamond (1971) proved that under imperfect information on offers (and even when the number of competitors is large) there is a unique, fully monopsonistic wage offered in equilibrium, which is identical to the bargaining solution where the employer has all the bargaining power. Because the rents that workers can capture disappear, there are no incentives for them to participate in the labour market when the cost of learning about offers is strictly positive. Wage dispersion becomes a possible solution when we allow workers to compare two offers simultaneously, as in Acemoglu and Shimer's model, or when they are allowed to search while employed for still better offers.

The model described in this paper endogenises a firm's choice of match-specific capital and wages simultaneously. It is important to note that the dispersion results do not follow from the possibility of choosing from a range of feasible capital levels. As in Acemoglu and Shimer (2000) and Mortensen (1998), I show that under mild and typical assumptions on the production function, there is a strictly increasing relationship between capital and wages in equilibrium, so that firms choosing to install more capital will pay higher wages and viceversa. Bontemps, Robin and van den Berg (1997) present a model with similar characteristics though productivity differences are assumed to be exogenous, mainly on account of its higher

This survey also includes an extensive discusses extensively the empirical literature on the estimation of matching functions in the labour market.

${ }^{2}$ This can be justified conveniently by setting the unit of time considered.

${ }^{3}$ See Mortensen and Pissarides (1999) for a discussion on the Diamond paradox. 
empirical tractability with matched firm-worker data. There is some empirical evidence suggesting a causal link from wages to technology, as presented in Chennells and van Reenen (1998) and Doms, Dunn and Torske (1997). This seems to justify the joint endogenisation of both capital and wage decisions. Dispersion results would also hold in the absence of capital decisions because wages are the only decision variable capable of affecting the probability to become and remain matched to a worker. By introducing capital into the model, more realistic distributions can be obtained. Otherwise, the nature of imperfect competition in wages would produce a strictly increasing wage density function up to the competitive equilibrium wage level.

This paper aims to focus more attention on the mechanism that pervades observed matching frictions in most markets, particularly the one in which labour is traded. Traditionally, the attention of researchers has been more directed at understanding what drives job search efforts and its associated costs. ${ }^{4}$ This objective is certainly not incompatible with a closer inspection of the matching technology black box, as this paper shows. I will provide an iterative procedure to find a numerical solution for an extended version of the wage posting model. This includes discretionary search efforts that result from the different incentives to search on-the-job depending on location in the wage distribution and the existence of search costs.

The article is structured as follows: Section 2 describes the economic environment and analyses the matching technology. The purpose of section 3 is to characterise and show the existence of a disperse equilibrium. The basic model is then extended to account for endogenous investments in job-specific human capital in section 4. Section 5 examines a more complicated version of the basic model with costly search and subsequent job search heterogeneity. The principal empirical implications of the 'micro-founded' matching model are discussed in section 6 . Section 7 concludes.

\section{Micro-foundations in a matching model of wage post- ing}

\subsection{The general setting}

The formal setup of the model does not contain a large number of elements and can be better described by exposing the sequence of decisions and events in each of the periods. At the beginning of each unit of time, which is discrete, an unspecified number of vacancies joins

\footnotetext{
${ }^{4}$ See for example Mortensen (1999) and Christensen et al (2001).
} 
those that remain unfilled from the previous period. The opening process for a new vacancy involves a managerial decision about the amount of worker-specific capital to be installed and the constant wage per period a successful applicant will earn. ${ }^{5}$ In the simplest version of this model, that will be used to describe the basic wage dispersion mechanism, I will assume there to be no quantitative investment decision. In that case, firms' decisions boil down to choosing whether to enter the market and what wage to post.

In this economy there is a measure $L$ of potential workers who are homogeneous in terms of skill and are either employed in some operating firm or unemployed, the latter being a proportion $u$ of the total. The maximum between the flow value of unemployment and the statutory minimum wage is denoted as $b$. This will be the minimum admissible wage offer that can be made by firms in an equilibrium.

The joint distribution of capital and wages among the total stock of vacancies $V$, old and new, is denoted by $F(k, w)$. The marginal distributions will be denoted as $F_{W}(w)$ and $F_{K}(k)$. Currently employed individuals are distributed across jobs according to the joint distribution $G(k, w) .{ }^{6}$ The matching process is described by a simple mechanism of job offer sampling and competing applications. In section 3, it will be assumed that each individual, whether employed or unemployed, finds out about a single vacancy in each period. This assumption has the following implications: (1) search intensity is homogeneous across the whole population; (2) by sampling a single offer per period, a firm whose vacancy has been detected by an individual has a certain monopsonistic power.

If it is in her interest, a given individual will choose to submit an application for the sampled offer at no cost. The success probability of this application will depend on the number of individuals who have actually applied for this particular job. After sampling, it is irrelevant whether or not this number is known to each one of the applicants as each individual has sampled a single offer. If a firm receives at least one application, the job will be assigned completely at random to only one of the applicants and the firm must commit to the wage previously posted. ${ }^{7}$ If, however, no applications are received at all, the vacancy will remain unfilled and the match process will be postponed until the next period.

This matching process implies that vacancies will not only be filled by previously unemployed individuals, but also by workers from other firms who choose to quit because of the more advantageous conditions (higher wages) in the new job. Endogenous job destruction follows from workers' random success in their search and application for better jobs. In this case, the worker-specific investment incurred by the firm when creating the job cannot be

\footnotetext{
${ }^{5}$ This model considers a fixed-coefficient technology such that one job can be occupied by a single worker.

${ }^{6}$ The marginal distributions are characterised by $G_{K}(k)$ and $G_{W}(w)$.

${ }^{7}$ In the case that there is a single applicant, he or she will obtain the job with probability one.
} 
recovered, forcing its exit from the market.

Once the matching market has closed, production takes place in non-vacant firms according to the function $\phi(k)$, which is assumed to be satisfy certain regularity conditions. These conditions include the requirements of being continuously twice differentiable, strictly increasing and concave in capital, with $\phi(a)=0$, for some $a>0, \phi^{\prime}(a) \rightarrow \infty$ and $\phi^{\prime}(\infty)=0$. Furthermore, attention will be restricted to functions for which it is possible to find a positive value $k_{0}$ for which 'average' and marginal product coincide in order to ensure a well behaved support for the optimal job creation decisions. Workers are paid the advertised wage and subsequently see themselves exposed to the exogenous probability $\delta$ that their job is destroyed. If this happens, workers become unemployed and firms face the same consequences as in the event of endogenous job destruction. This concludes a unit of time in this economy. New vacancies may join the currently existing stock (unmatched firms) and the same process is continuously repeated over time.

Both workers and firms discount the future with factor $\beta$ and are assumed to be risk neutral. Workers are considered to be utility maximisers. In the context of this model, their behaviour is substantially simplified to an application strategy consisting of an application to any job offering more than their current remuneration when employed or more than $b$ when unemployed. This simplification will be more carefully examined when endogenous search intensity is allowed for. In order to simplify the equilibrium characterisation, I will adopt the convention that when faced with two identical choices, the individual chooses to move to the new offer. In equilibrium this assumption will be unimportant because of the zero-probability of such an event.

Probably the most significant assumption of this setting is the assumption of dual perfect commitment. Workers cannot put pressure on their employers to increase their wages under the threat of moving to another job. Informational problems can be invoked to justify this approach, as a worker's threat may not be credible - particularly if there is no contractual agreement that punishes workers for announcing "fake" offers. On the other hand, this assumption restricts the possibility that firms will exploit the existence of many candidates to pay the minimum of the candidates' reservation wages, and default on their previous promises once a worker has left their previous job. Wage commitment could be therefore the result of an efficiency-enhancing institutional arrangement.

This model is an equilibrium approach to the phenomenon of wage dispersion and matching. As such, some restrictions need to be imposed on the way agents formulate expectations. Firms have a complete understanding of the effect of their wage offers on the probability of receiving at least one application as well as on the probability of losing a worker to a competitor firm. In spite of the informational burden that placed on individuals and firms, 
this model follows most of the existing literature by only considering rational expectations steady-state equilibria with perfect foresight.

\subsection{Matching probabilities}

The probability that a randomly chosen individual applies to a job paying $w$ is given by $\frac{1}{V}\left(u+(1-u) G_{W}(w)\right)$. This is just the joint probability that this particular individual observes the vacancy and that this offer is attractive enough for her to make an application. With $L$ individuals, the probability of not receiving any application at all is given by: ${ }^{8}$

$$
p(w)=\left[1-\frac{1}{V}\left(u+(1-u) G_{W}(w)\right)\right]^{L} .
$$

If we define $q=L / V$ as the inverse of 'market tightness', as this expression is known in the literature, and assess what happens when the number of individuals and vacancies becomes large $(L, V \rightarrow \infty)$, this probability becomes approximately:

$$
p(w)=1-e^{-q\left[u+(1-u) G_{W}(w)\right]} .
$$

Denote $\mathcal{W}$ as the set of wages offered in equilibrium. The probability of losing a worker to another firm is

$$
\chi(w)=\int_{\{\tilde{w} \in \mathcal{W}: w \leq \tilde{w}\}} s(\tilde{w}) d F(\tilde{w}),
$$

where $s(\tilde{w})$ represents the probability that an application to a job $\tilde{w}$ is successful. This expression integrates the application success probability over the set of desirable wage offers, taking into account their density. The probability that an individual faces a number $i$ of competitors for a job that she has sampled is given by ${ }^{9}$

$$
\frac{(L-1) !}{i !(L-1-i) !}\left(\frac{u+(1-u) G_{W}(w)}{V}\right)^{i}\left(1-\frac{u+(1-u) G_{W}(w)}{V}\right)^{L-1-i} .
$$

The first term indicates the number of possible combinations that will deliver an identical number of competitor applicants 'i', out of the population $L-1$ of potential competitor

\footnotetext{
${ }^{8}$ This statement is not entirely accurate. The probability that no individual applies to a job offering $w$ is actually given by $(1-1 / V)^{U} \prod_{i \in \text { Employment }}\left(1-\frac{\mathbf{1}\left(w_{i} \leq w\right)}{V}\right)$, where $\mathbf{1}(A)=1$ if the event $A$ is true and 0 otherwise. The approximation described in the main text will converge to the same value as that derived from the true probability when the population size becomes arbitrarily large, as it is assumed in this model, as a result of the law of large numbers.

${ }^{9}$ Once more, this statement is not accurate for finite populations but the law of large numbers ensures the convergence to this same probability. This specification is chosen strictly for presentational purposes.
} 
applicants. ${ }^{10}$ The product of the remaining two terms represents the probability that a particular group of 'i' individuals apply for a given job paying $w$.

With $i$ competitors, the application will succeed with probability $1 /(1+i)$. As a consequence, an individual's assessment of her probability of success when applying for a job offering $w$ is defined as follows:

$$
\begin{aligned}
s(w) & =\sum_{i=0}^{L-1} \frac{1}{1+i} \frac{(L-1) !}{(L-1-i) ! i !}\left(\frac{u+(1-u) G_{W}(w)}{V}\right)^{i}\left(1-\frac{u+(1-u) G_{W}(w)}{V}\right)^{L-1-i} \\
& =\frac{1}{q\left[u+(1-u) G_{W}(w)\right]}\left[1-\frac{1}{V}\left[u+(1-u) G_{W}(w)\right]\right]^{L}
\end{aligned}
$$

which, as $V$ becomes large, approximates:

$$
s(w)=\frac{1-e^{-q\left[u+(1-u) G_{W}(w)\right]}}{q\left[u+(1-u) G_{W}(w)\right]} .
$$

Notice that the success application function $s(w \mid U, L-U, V)$ is homogeneous of degree zero in $U, L-U$ and $V$, for any given $w$. By increasing the measure of vacancies, unemployment and the population by the same factor, the unemployment rate and the inverse of market tightness $(L / V)$ do not change. This is also true for the vacancy matching probability $p(w \mid U, L-U, V) .{ }^{11}$ This is a substantially revised version of the standard random matching technology criticised by Petrongolo and Pissarides (2000). According to this specification, the model gains not only in terms of micro-foundations, but also improves with regard to the richer interaction between the wage distribution and matching patterns, as described in Holzer et al (1991).

It is reasonable to consider that an approximation to a continuum of individuals and firms is adequate in the case of the labour market. This is convenient when imposing the assumption that an individual firm will not be able to perceive the effect of her own actions on the structure of the market. ${ }^{12}$ Additionally, as is commonly found in most of the Economics literature, I will assume that there is perfect foresight of the future distributions of wages and capital among vacant and non-vacant firms, and perfect knowledge of the measure of

\footnotetext{
${ }^{10}$ Obviously, the individual excludes him/herself from this computation.

${ }^{11}$ I will also normalise the measure of the population $L$ to one, so that $q=1 / V$.

${ }^{12}$ I choose not to carry on by approximating the matching setup to a continuous time framework because the nature of frictions crucially depends on the possibility of more than one offer being received by a firm simultaneously. This essential congestion feature vanishes in continuous time unless the number of searching agents grows faster than the divisions of a unit of time. In the real world, it is rare to attend one job interview without any additional candidates. Further research is needed on the different limiting properties of micro-founded frictions.
} 
vacancies and unemployed workers at each period of time. As the focus is strictly on steadystate equilibria, it will necessary to impose additional constraints on the time invariance of these distributions and variables.

\section{The basic model: wage dispersion without capital}

In this section, I concentrate on showing the key aspects of a labour market equilibrium in a slightly simpler version of the model described above. The only difference is the assumption that there is no choice of job-specific capital by firms and thus the firm only makes decisions about market participation and wage posting. The purpose is to show that none of the key features of the model hinge on the assumption of job-specific capital. As stated above, wage dispersion follows from the trade-off between standard profits in each period a worker is employed in a job and the likelihood of filling a vacancy.

Here I assume that $\gamma$ denotes the fixed cost associated with creating a job. Without capital and given identical workers, productivity per period must be constant. In order to simplify the notation, productivity can be normalised to one without loss of generality, and I will omit the sub-index $W$ from the distribution functions $F$ and $G$.

\subsection{Job creation and Bellman equations}

The value $J^{V}(w)$ of opening a vacancy promising a wage $w$ is given by:

$$
J^{V}(w)=\left(1-e^{-q\left[u+(1-u) G_{W}(w)\right]}\right) J^{F}(w)+e^{-q\left[u+(1-u) G_{W}(w)\right]} \beta J^{V}(w) .
$$

A given vacancy remains unmatched with probability $1-p(w)=e^{-q[u+(1-u) G(w)]}$, that is, the probability that no worker at all decides to apply for it. In this case, the expected value falls according to the discount factor $\beta$. Otherwise, the value of a firm coincides with the value of having filled a vacancy $J^{F}(w)$, which is determined by:

$$
J^{F}(w)=1-w+\beta(1-\delta)(1-\chi(w)) J^{F}(w) .
$$

The value of a filled vacancy can be decomposed into its flow value, which is determined by the difference between the normalised output and the wage rate $1-w$ plus its capital value. The latter depends on the compound probability that the job is not destroyed by either exogenous or endogenous (quit) reasons. Job destruction leads to a future value of zero, whereas persistence ensures the properly discounted value of a filled vacancy $\left(\beta J^{F}(w)\right)$.

The cost of opening a vacancy is given by the exogenously fixed price price $\gamma$. Therefore, the net value of a vacancy $J^{N V}(w)$ is expressed as follows: 


$$
J^{N V}(w)=J^{V}(w)-\gamma=\frac{1-e^{-q[u+(1-u) G(w)]}}{1-\beta e^{-q[u+(1-u) G(w)]}} \frac{1-w}{1-\beta(1-\delta)(1-\chi(w))}-\gamma
$$

Let us denote $\mathcal{W}$ as the set of wage offers made in equilibrium. Any element of this set $w \in \mathcal{W}$ must satisfy the condition that there is no other wage offer $w^{\prime}$ such that $J^{N V}\left(w^{\prime}\right)>$ $J^{N V}(w)$. Furthermore, the absence of restrictions on creating vacancies implies a typical zero profit condition, i.e. $J^{N V}(w)=0$ for any $w \in \mathcal{W}$. In that case:

$$
\gamma=\frac{1-e^{-q[u+(1-u) G(w)]}}{1-\beta e^{-q[u+(1-u) G(w)]}} \frac{1-w}{1-\beta(1-\delta)(1-\chi(w))} .
$$

It is now necessary to derive additional features of an equilibrium. This will involve determining which constraints are necessary to ensure the stationarity of the equilibrium and the restrictions on the support of the wage and capital distributions.

\subsection{Steady-state conditions and equilibrium characterisation}

Now let us examine the conditions for a steady-state equilibrium in this economy. The minimum of the set of wages offered in equilibrium must be equal to $b{ }^{13}$ It is obvious that it cannot be smaller, as firms would not attract any workers at all when the statutory minimum wage is not binding relative to the flow value of unemployment. ${ }^{14}$ The equilibrium minimum wage cannot be strictly larger than $b$. To prove this, let us suppose there were another minimum value $w_{\min }$ such that $w_{\min }>b$. A firm offering this wage would only attract unemployed individuals and workers being paid the same amount $w_{\min }$ in their current jobs. A marginal reduction in the wage offered to a level above or equal to $b$ would not affect the application probabilities from the unemployed, would increase operational profits but it might imply some reduction in the probability of attracting workers being paid $w_{\min }$. However, the latter effect would be negligible as it is impossible to have an atom at $w_{\text {min }}$. The explanation is as follows: if there were a mass of firms offering and paying such an amount, there would be incentives to deviate by offering a marginally larger wage with a consequent discrete gain in the probability of attracting and retaining workers.

Moreover, there can not be an atom in the set of offers. The same argument as above would apply. Firms have incentives to deviate from an eventual mass point in the distribution

\footnotetext{
${ }^{13}$ This discussion is not entirely rigorous, as I do not distinguish between the concepts of supremum and infimum and the associated concepts of maximum and minimum.

${ }^{14}$ I do not entertain the possibility that firms do not comply with regulations and pay less than the statutory minimum wage.
} 
by making marginally larger wage offers. This is on account of the positive measure of workers who would become attracted to the firm at a negligible wage cost. The maximum value $\bar{w}$ of the support for $\mathcal{W}$ implies $G(\bar{w})=1$. It is not possible to have an atom at this point because $\chi(w)$ would be positive and there would be incentives for a firm to offer a marginally larger wage.

It is also possible to show that $\mathcal{W}$ is a convex set. Imagine that, all wage $w$ such that $w_{1}$ and $w_{2} \in \mathcal{W}$ and $w_{1}<w<w_{2}$, satisfy $w \notin \mathcal{W}$. If this were true, firms offering $w_{2}$ would have incentives to reduce their wage offers to a level very close to $w_{1}$ without affecting the probabilistic terms in their value functions, thus increasing expected profits and contradicting the possibility of such type of equilibrium.

The previous arguments show that the distribution of wage offers and jobs will be continuous on the closed interval $\mathcal{W}$ delimited by $b$ and $\bar{w}$, that satisfy $F(b)=G(b)=0$ and $F(\bar{w})=G(\bar{w})=1$.

Now let us turn our attention to the dynamics of the model. In a steady state equilibrium, it is required that even though individuals transit from one state to another, the general characteristics of the economy remain constant. This implies that for any given wage, the number of workers earning less than this quantity remain constant over time and so the number of vacant jobs and unemployed individuals also remain constant.

If we call $T[w]$ the number of individuals with a flow value less than or equal to $w,{ }^{15}$ we will need to impose the condition that the inflow into this group is exactly balanced by the corresponding outflow

$$
\delta(1-T[w])=(1-\delta) T[w] \chi(w)
$$

where the inflow is the measure of workers earning more than $w$ who enter the stock $T[w]$ when they lose their jobs. The outflow denotes the proportion of $T[w]$ that move into better jobs and manage to preserve them at least until the end of the time period considered.

Notice that if equation (6) is evaluated at $w=b$, a condition follows on the required constant measure of unemployment $u$. This balance is defined by the following equation:

$$
\delta(1-u)=(1-\delta) \chi(b) u
$$

which implies the following value for the unemployment rate:

$$
u=\frac{\delta}{\delta+(1-\delta) \chi(b)} .
$$

\footnotetext{
${ }^{15}$ This includes also all the unemployed if $\mathrm{b} \leq \mathrm{w}$.
} 
This rate depends on the exogenous job destruction parameter $\delta$ and the endogenous rate $\chi(b)$. It is important to note that the latter is not a trivial function of the market tightness, as an aggregate matching technology model would imply.

Moving back to the general steady-state dynamics of $T[w]$, it is possible to state:

$$
\chi(w)=\frac{\delta}{1-\delta}\left(\frac{1}{T[w]}-1\right) .
$$

This must be true for all $w \in \mathcal{W}$. If we assume that the continuous distributions distributions $F$ and $G$ are differentiable, the following will be true:

$$
\chi^{\prime}(w)=-\frac{\delta}{1-\delta} \frac{T^{\prime}[w]}{T[w]^{2}} .
$$

Now we can consider the definition of the quit rate $\chi(w)$.

$$
\chi(w)=\int_{w}^{\bar{w}} \frac{1-\exp (-q T[\hat{w}])}{q T[\hat{w}]} d F(\hat{w}) .
$$

Differentiating with respect to $w$ :

$$
\chi^{\prime}(w)=-\frac{1-\exp (-q T[w])}{q T[w]} F^{\prime}(w) .
$$

It is possible to equate the expressions for $\chi^{\prime}(w)$ derived from (8) and (9) for all $w \in \mathcal{W}$.

$$
\frac{\delta}{1-\delta} \frac{T^{\prime}[w]}{T[w]}=\frac{1-\exp (-q T[w])}{q} F^{\prime}(w) .
$$

Alternatively, this can be rewritten as follows:

$$
\frac{F^{\prime}(w)}{T^{\prime}(w)}=\frac{\delta}{1-\delta} \frac{q}{T[w](1-\exp (-q T[w]))} .
$$

It is obvious that the equation above is autonomous of $w$. Thus, everything can be rewritten as the following differential equation, relating the offer distribution and the measure of workers $T=T[w]$ with flow values below $w$.

$$
\frac{d \tilde{F}}{d T}=\frac{\delta}{1-\delta} \frac{q}{T(1-\exp (-q T))} .
$$

This equation does not have an analytical solution, although it can be solved numerically. This requires some boundary conditions. First, we know that $F(b)=0$ and $T(b)=u$ because the measure of individuals earning an amount less than or equal to $b$ is the measure of unemployment, since there is no mass point of wage offers at $b$. Additionally, when $w=\bar{w}$, 
$F(\bar{w})=T(\bar{w})=1$. Hence, if we consider the transformed function $\tilde{F}(T)=F(w(T))$, where $w(T)$ is the inverse of $T=T(w)$, we get $\tilde{F}(u)=0$ and $\tilde{F}(1)=1$. Thus:

$$
\int_{0}^{F(w)} d \tilde{F}=\int_{u}^{T(w)} \frac{\delta}{1-\delta} \frac{q}{T(1-\exp (-q T))} d T
$$

For a given value of $q$ and $u$, this expression relates the distribution of offers to the distribution of wages across employed individuals. Such values still need to be determined. To achieve this, one can evaluate equation (10) at $w=\bar{w}$, i.e., at $T=1$ :

$$
1=\int_{u}^{1} \frac{\delta}{1-\delta} \frac{q}{T(1-\exp (-q T))} d T .
$$

This equation defines a positive relationship between $q$ and $u$. As $u$ increases, the integrand term (which is always positive) must decrease in order to compensate for the reduction in the integration interval. This must be achieved by increasing $q$, i.e. reducing the number of vacancies. This is the typical Beveridge Curve expression which is frequently cited in the matching literature. It is the outcome of combining the pairs $(u, q)$ which satisfy equation in (10). One way to plot this set is to fix $q$ and solve the differential equation with numerical methods using only the constraint that $F(T=1)=1$ : the associated unemployment rate is given by the intersection of the $\tilde{F}(T)$ function with the $x$ axis, since $0=\tilde{F}(T=u)$.

\section{Figure 1: Determination of steady-state consistent $u$ for values of $q$}

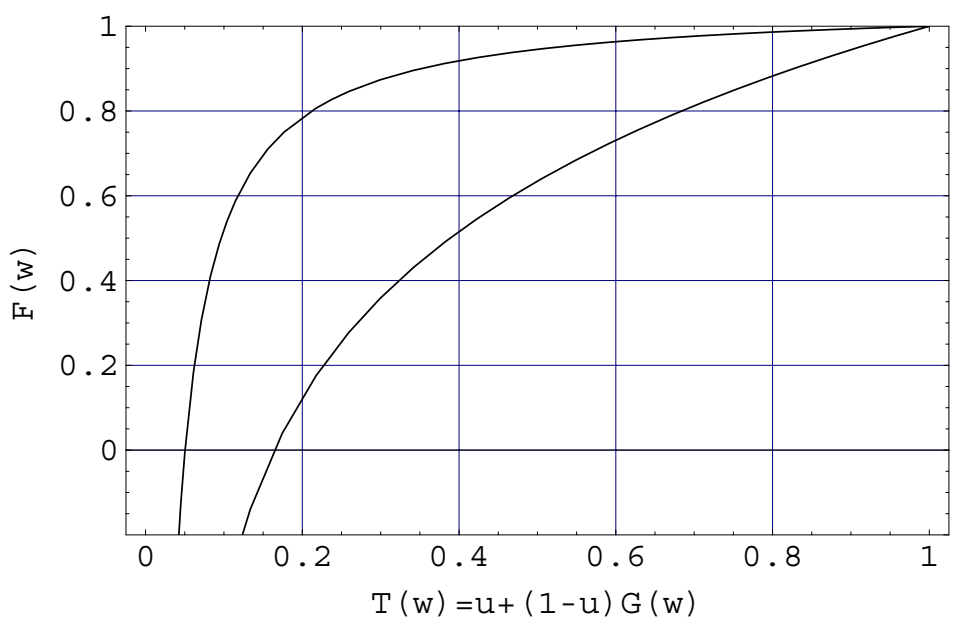

Exogenous destruction rate $\delta=0.05 . q_{H}=10, q_{L}=.1$.

Figure 3.2 depicts the graphic determination of the value $u$ defined by two different values for $q$ implied by equation (11). As explained above, the upper curve corresponds to a lower 
level of $q$ i.e, a higher number of vacancies. The intersection of the other curve (corresponding to a higher $q$ ) with the $x$-axis indicates that the only consistent unemployment rate in steady state will be lower.

Another implication of the steady-state equilibrium is that the actual wage distribution stochastically dominates the wage offer distribution in the sense that for all $w \in \mathcal{W}, G(w) \leq$ $F(w)$. This can easily be observed in figure 3.2. Since $T[w]$ is strictly increasing in $w$ in the equilibrium support, it is sufficient to observe that $\tilde{G}(T) \leq \tilde{F}(T)$ for all $T \in[0,1]$. Given the model's assumptions, $\tilde{G}$ is a linear function of $T$ which we observe to lie strictly below $\tilde{F}$ except for $T=0$ and $T=1$, where they coincide. In conclusion, the distribution of actual paid wages is better than that of offers because of the mobility of individuals towards better paid jobs. Filled jobs are more likely to be associated with higher wages than those unfilled, which are a combination of old and new vacancies.

\section{Figure 2: Stochastic dominance of paid wages over wage offers}

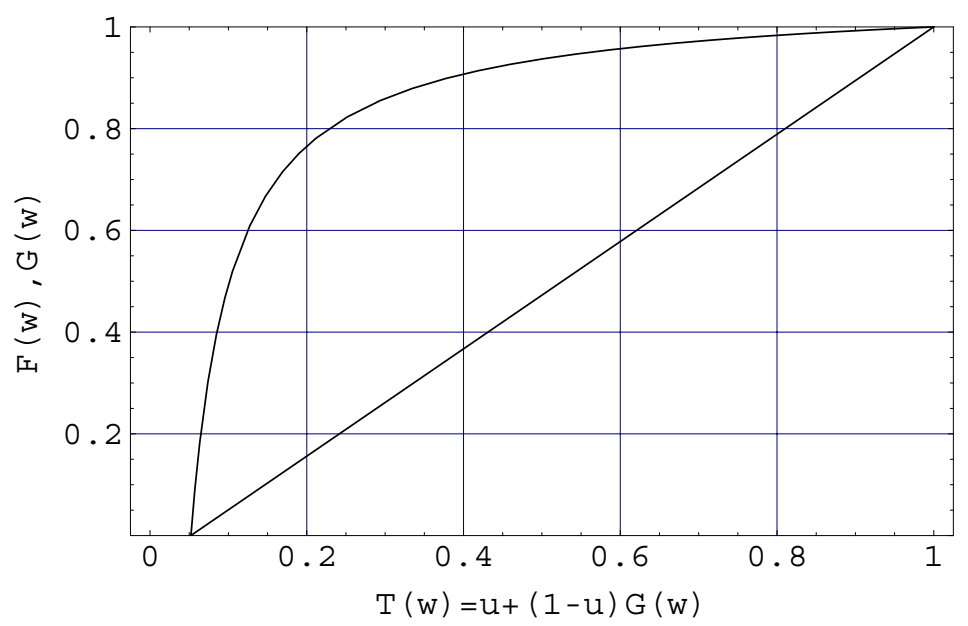

Now it is possible to derive the conditions under which an equilibrium exists. The additional expression that relates unemployment to vacancies (or its inverse in $q$ ) follows from the zero profit condition, evaluated at the infimum of the equilibrium wage support $b$. Imposing $\chi(b)=\delta(1-u) /((1-\delta) u)$, it states

$$
\gamma=\frac{1-\exp (-q u)}{1-\beta \exp (-q u)} \frac{1-b}{1-\beta(1-\delta / u)} .
$$

This defines a negative relationship between $q$ and $u$. This is the typical job creation condition in the literature. To preserve the entry/exit equilibrium in the market, if there is a 
higher value of unemployment (which increases the pool of applicants for jobs), the number of vacancies must increase ( $q$ must decrease) in order to compensate. As a result of this, there is a strictly decreasing relationship between $u$ and $q$.

Combining equations (12) and (11), it is possible to see that there will be at most a single (non-degenerate) equilibrium in this economy. To show its existence in a simple way, notice that $\left.\left(q_{z p c}(u)-q_{d y n}(u)\right)\right|_{u \rightarrow 0}<0$ and $\left.\left(q_{z p c}(u)-q_{d y n}(u)\right)\right|_{u \rightarrow 1}>0 .{ }^{16}$ The continuity and monotonicity of $q_{z p c}(u)-q_{d y n}(u)$, together with the feasibility condition $b<1$, ensures that there is a unique equilibrium $\left(u^{*}, q^{*}\right)$ such that $0<u^{*}<1$ and $0<q^{*}<\infty$.

Once the equilibrium pair $\left(u^{*}, q^{*}\right)$ has been found, it is possible to derive the maximum wage rate paid in equilibrium. This is defined by:

$$
\gamma=\frac{1-\exp \left(-q^{*}\right)}{1-\beta \exp \left(-q^{*}\right)} \frac{1-\bar{w}}{1-\beta(1-\delta)}
$$

because $\chi(\bar{w})=0$. The distribution of wages across employed individuals is now easy to derive. First, it is possible to derive the quit rate function $\chi(w)$ because the zero profit condition establishes an implicit function of the form $\Gamma[w, \chi(w) \mid q, u]=0$.

From $T[w]=\frac{\delta}{\delta+(1-\delta) \chi(w)}$, as implied by equation (6), the zero profit condition becomes:

$$
\gamma=\frac{1-\exp \left(-q^{*} \delta /(\delta+(1-\delta) \chi(w))\right)}{1-\beta \exp \left(-q^{*} \delta /(\delta+(1-\delta) \chi(w))\right)} \frac{1-w}{1-\beta(1-\delta) \chi(w)} .
$$

If we set $\chi(w)=x$ we can state that:

$$
w=1-\gamma \frac{(1-\beta(1-\delta) x)\left(1-\beta \exp \left(-q^{*} \delta /(\delta+(1-\delta) x)\right)\right)}{1-\exp \left(-q^{*} \delta /(\delta+(1-\delta) x)\right)} .
$$

This defines an equilibrium wage rate for each possible wage rate $x$. It should be noted that $w$ is a strictly decreasing function of $x$ in $[0,1]$ for any positive value of $q^{*}$. Therefore, this can be inverted and the quit probability will fall as the wage increases. Once $\chi(w)$ is known, the derivation of the wage distribution across filled jobs $G$ is straightforward using $T[w]=u^{*}+\left(1-u^{*}\right) G(w)=\frac{\delta}{\delta+(1-\delta) \chi(w)}$. This is shown in figure 3.2.

With $T[w]$ known, the steady-state dynamic differential equation relating $T$ to $F$ can produce numerical solutions for $F$ given $T$ at any given wage value $w$.

The equilibrium distribution of wages appears to have an increasing density. This feature is shared by the models in Burdett and Mortensen (1997) and Mortensen (1998) in which wages are the only attribute of a job. In equilibrium, employers concentrate their offers near the competitive equilibrium wage level. Thus, frictions in this market tend to push employers

\footnotetext{
${ }^{16}$ The functions $q_{d y n}(u)$ and $q_{z p c}(u)$ represent the values of $q$ implicitly defined by the steady state dynamics condition and the zero profit constraint, respectively, for a given value of $u$.
} 


\section{Figure 3: Equilibrium wage distribution}

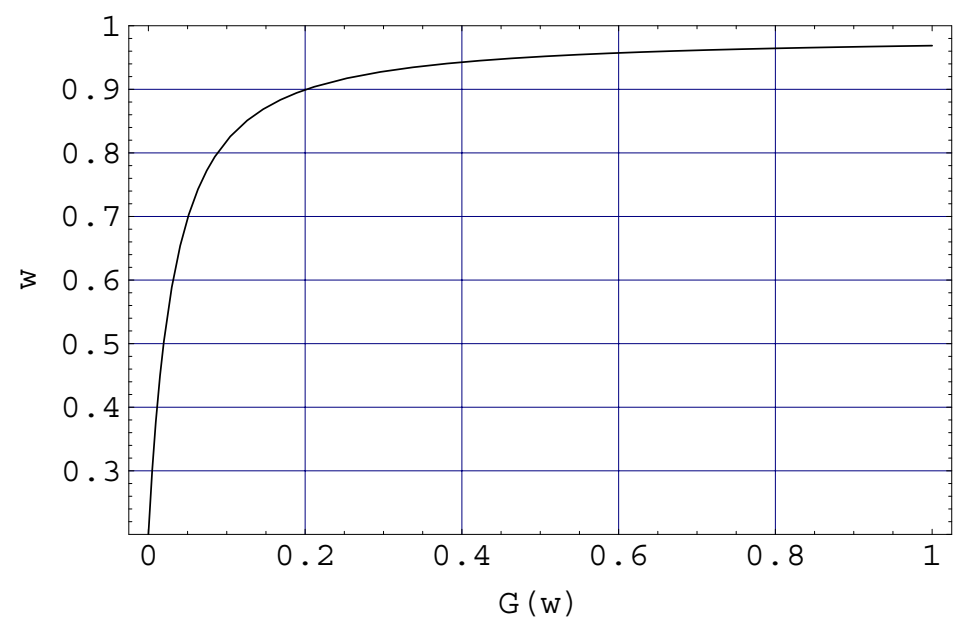

Parameter values: $\delta=0.05, \gamma=0.03, \beta=0.95, b=0.02$.

Equilibrium values: $u^{*}=0.052, q^{*}=0.536, \bar{w}=.96869$.

away from the competitive offers towards the minimum wage rate. The next section will show how it is possible to obtain more realistic, positively skewed distributions by allowing discretionary choices of job-specific capital by employers. The presence of decreasing returns to capital implies that, in equilibrium, offers will not be so concentrated just below the competitive level.

\section{Wage dispersion and investment in job-specific hu- man capital}

The extension of the basic model to the more general setting with capital choices is quite straightforward. With job-specific capital investments by the employer, it will be possible to extend the process of wage differentiation to an additional dimension. The basic mechanism at work is as follows: under standard assumptions about the productivity and cost of capital, there will be a unique investment decision associated with each wage offer. Firms that offer low wages can anticipate a longer waiting period until hiring a worker and a higher probability that a worker will find a better job and decide to quit. Such firms have an obvious disincentive to invest a lot of resources in job-specific capital. The opposite applies to firms offering high wages. Let us examine this model in more detail. 
The value $J^{V}(k, w)$ of opening a vacancy with capital $k$ and ofering wage $w$ is given by

$$
J^{V}(k, w)=\left(1-e^{-q\left[u+(1-u) G_{W}(w)\right]}\right) J^{F}(k, w)+e^{-q\left[u+(1-u) G_{W}(w)\right]} \beta J^{V}(k, w),
$$

with matching probability $p(w)=1-e^{-q\left[u+(1-u) G_{W}(w)\right]}$, in which case the firm obtains the value $J^{F}(k, w)$ of having filled a vacancy:

$$
J^{F}(k, w)=\phi(k)-w+\beta(1-\delta)(1-\chi(w)) J^{F}(k, w) .
$$

The flow value of a filled vacancy is now determined by the difference between output and wages $\phi(k)-w$. All the additional elements remain unchanged relative to the basic model, except for the cost of opening a vacancy. This is given by the product of the job-specific capital $k$ and its constant and exogenous price $\gamma$. Therefore, the net value of a vacancy $J^{N V}(k, w)$ is expressed as follows:

$$
\begin{aligned}
J^{N V}(k, w) & =J^{V}(k, w)-\gamma k \\
& =\frac{1-e^{-q\left[u+(1-u) G_{W}(w)\right]}}{1-\beta e^{-q\left[u+(1-u) G_{W}(w)\right]}} \frac{\phi(k)-w}{1-\beta(1-\delta)(1-\chi(w))}-\gamma k .
\end{aligned}
$$

Let us denote $\mathcal{E}$ as the set of capital and wage offers in equilibrium. Any element of this set $\{k, w\} \in \mathcal{E}$ must satisfy the condition that there may not exist another pair $\left\{k^{\prime}, w^{\prime}\right\}$ such that $J^{N V}\left(k^{\prime}, w^{\prime}\right)>J^{N V}(k, w)$. Besides, the absence of restrictions towards opening vacancies implies a typical zero profit condition, i.e. $J^{N V}(k, w)=0$ for any pair $\{k, w\} \in \mathcal{E}$.

Since $J^{N V}(k, w)$ is strictly concave in $k$, it must be true at the optimum that $\frac{\partial J^{N V}(k, w)}{\partial k}=$ 0. This implies:

$$
\frac{1-e^{-q\left[u+(1-u) G_{W}(w)\right]}}{1-\beta e^{-q\left[u+(1-u) G_{W}(w)\right]}} \frac{\phi^{\prime}(k)}{1-\beta(1-\delta)(1-\chi(w))}=\gamma .
$$

Substituting this expression back into the zero profit condition, the following expression will hold for wages:

$$
w=W(k) \equiv \phi(k)-k \phi^{\prime}(k) .
$$

This defines the optimal wage offer as a continuous monotonically increasing function of the optimal investment decision. ${ }^{17}$

\footnotetext{
${ }^{17}$ If a firm decided to pay the minimum feasible wage, $w=b$, then it must be possible to invest in the corresponding amount of capital. For this amount to be non-negative, it is necessary that there exists a value $k_{0}$ such that $\frac{\phi\left(k_{0}\right)-b}{k_{0}}=\phi^{\prime}\left(k_{0}\right)$. For example, the production function $\phi(k)=A(k-a)^{\alpha}$ satisfies this assumption, although it is not possible to find a closed form expression for $k_{0}$ unless $b=0$. In that case, $k_{0}=a /(1-\alpha)$.
} 
Equation (15) implies that $G_{K}(k)=G_{W}(W(k))$. Thus, the zero profit condition can be re-written strictly in terms of capital. The dimensionality of the problem is thus reduced.

$$
\gamma=\frac{1-e^{-q\left[u+(1-u) G_{W}(W(k))\right]}}{1-\beta e^{-q\left[u+(1-u) G_{W}(W(k))\right]}} \frac{\phi^{\prime}(k)}{1-\beta(1-\delta)(1-\chi(W(k)))} .
$$

The requirements of the equilibrium distribution of offers have not changed. It is sufficient to state the boundaries in terms of either of the two variables considered, capital and wages. Since the dimension of the problem is reduced to expressing everything in terms of capital, it will be true that the highest investment level $\bar{k}$ satisfies $G_{K}(\bar{k})=1$ and the lowest will be the capital level $k_{0}$ such that $W\left(k_{0}\right)=b$.

Again, it is possible to show that the zero profit condition evaluated at $k_{0}$ and equation (11) determine $u$ and $q$. Figure 4 illustrates this in the same way as in the case without capital investments.

\section{Figure 4: Equilibrium determination with capital}

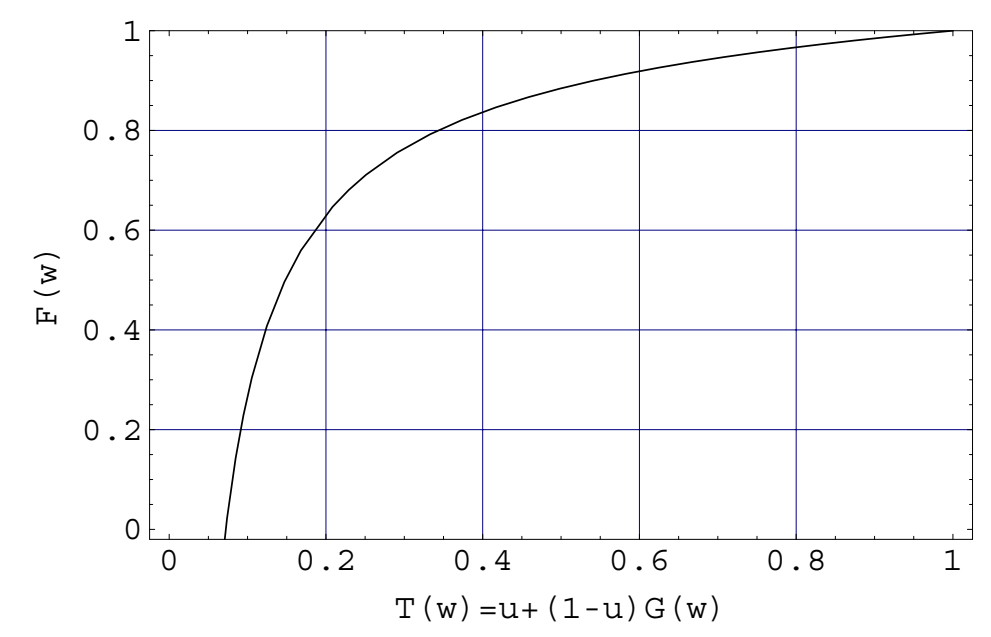

Parameter values: $\delta=0.06, \beta=0.9, b=2, \gamma=0.1, A=0.5, a=1, \alpha=0.7$.

Equilibrium values: $k_{0}=44.75, u^{*}=0.072, q^{*}=1.9137$.

The highest capital value in equilibrium can be derived from equation (16) using $G_{W}(W(\bar{k}))=$ 1 and $\chi(W(\bar{k}))=0$. Finally, the distribution of capital $G_{K}(k)$ can easily be derived by inverting the monotonically increasing relationship between $k$ and $G_{W}(W(k))=G_{K}(k)$ in (16) after the pertinent substitutions. Figures 5 and 6 depict the wage and capital distributions across filled jobs. 


\section{Figure 5: Equilibrium distribution of job-specific capital}

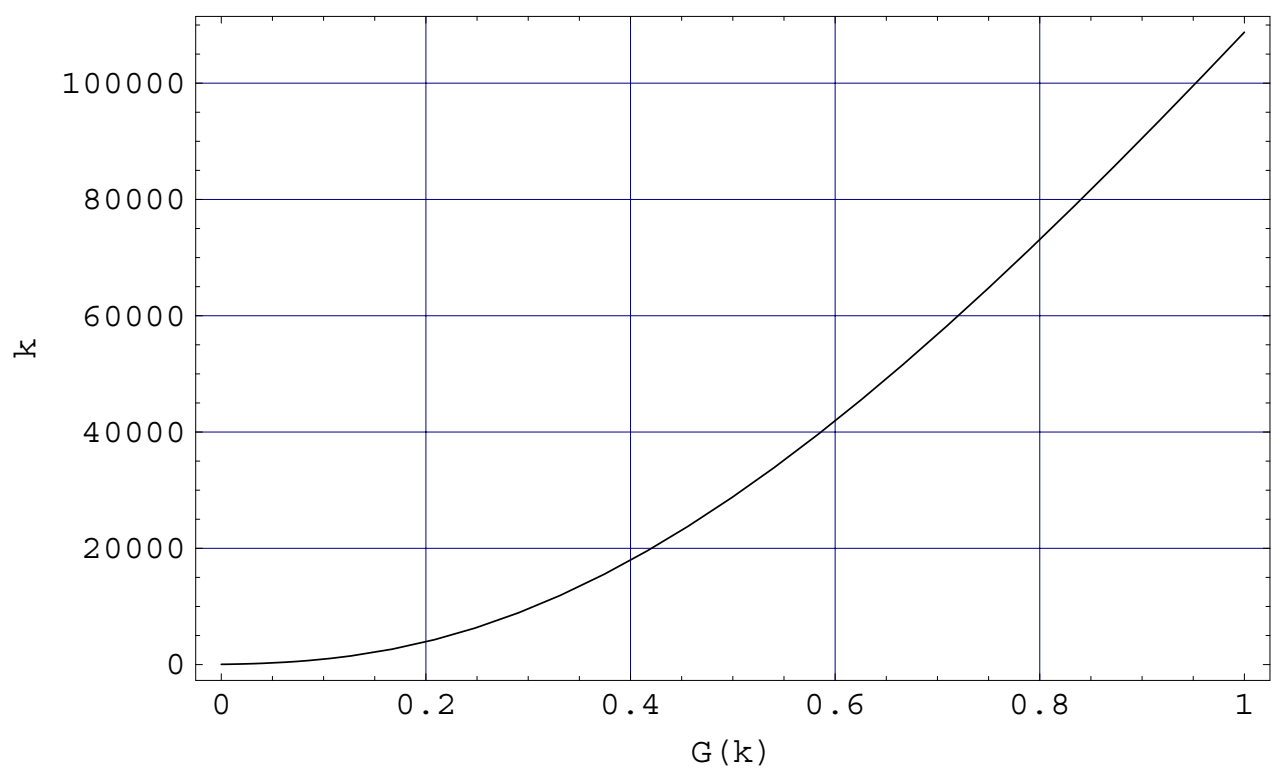

Parameter values: Same as in figure 4.

Equilibrium values: Idem. $\bar{k}=108762$.

These figures show how the introduction of job-specific human capital can help generate more plausible wage and capital distributions with a positive skew. Decreasing returns to capital lead firms to locate themselves further away on average from the maximum wage (and capital) equilibrium level.

It can also be proven that the timing of job-specific capital investment is a non essential element of this result. For example, if a firm can wait until the match is made to choose the level of $k$, it will maximise the following expression, conditional on $w$ :

$$
\max _{k \in \Re^{+} \cup\{0\}}\left\{\frac{\phi(k)-w}{1-\beta(1-\delta)(1-\chi(w))}-\gamma k\right\} .
$$

Given the assumptions made on $\phi$ there will be an interior solution determined by

$$
\phi^{\prime}(k)=\gamma(1-\beta(1-\delta)(1-\chi(w)))
$$

for all $\{w, k\} \in \mathcal{E}$ and this implies the following relationship:

$$
\phi^{\prime \prime}(k) k^{\prime}(w)=\gamma \beta(1-\delta) \chi^{\prime}(w) .
$$




\section{Figure 6: Equilibrium distribution of wages}

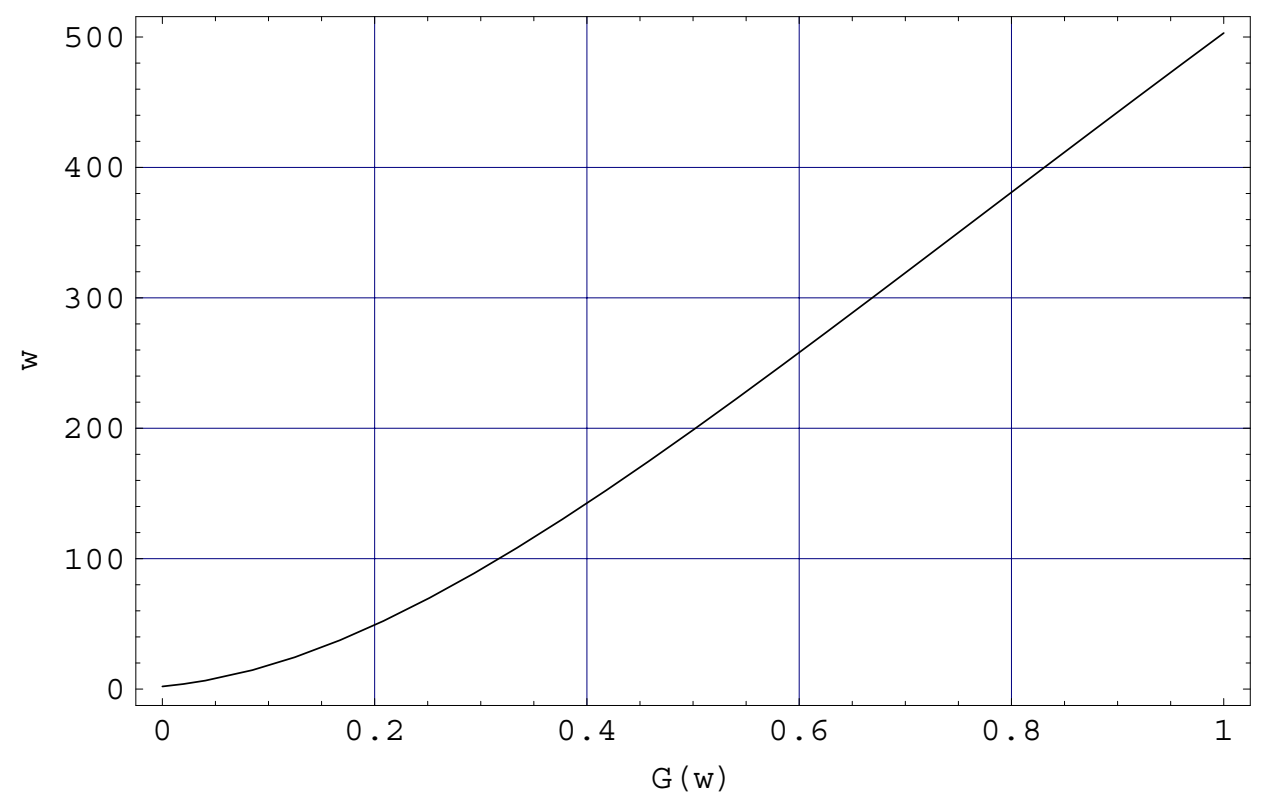

Parameter values: Same as in figure 4.

Equilibrium values: Idem. $\bar{w}=503.05$.

This states that the optimal capital choice $k$ is a strictly increasing function of $w$ because of the concavity of $\phi$ and the fact that the quit probability $\chi(w)$ is strictly decreasing in the wage distribution support.

\section{Endogenous search efforts}

It is reasonable to argue that individual search intensity is not homogeneous across the labour force. Keeping everything else constant, unemployed individuals are, in principle, the most likely to benefit from sampling one job offer because this new offer may be expected to be at least as good as their current situation. In contrast, a worker with a reasonably high position in the wage distribution has a lower probability of finding a job offer that can improve her existing position. The existing diversity in terms of the potential benefits of sampling from the job offer distribution, combined with a process of costly search, dictates that higher earning individuals should exert a lower search effort. This section formalises this 
intuition within the matching function environment specified above. To ease presentation, I will return to the case without quantitative investment decisions.

\subsection{The model}

Instead of allowing all individuals to sample one offer from the pool of job vacancies at no cost, I assume that with cost $c(\sigma)$ an individual can sample an offer with probability $\sigma$. The function $c(\sigma)$ is assumed to be twice continuously differentiable, increasing and convex in the sampling probability $\sigma$ and satisfying $c(0)=c^{\prime}(0)=0$ and $c(1)=c^{\prime}(1) \rightarrow \infty$, in order to ensure that an interior solution exists.

Let us assume for a moment that for each wage level $w$ there is an associated search effort $\sigma(w)$. Again, the term $T(w)$ is used to denote the expected number of applicants for a job paying $w$. With possible heterogeneous search efforts this will be determined by:

$$
T(w)=u \sigma(b)+(1-u) \int_{b}^{w} \sigma(z) d G(z) .
$$

Thus, the probability that the firm offering a wage $w$ will receive an application is

$$
p(w)=1-e^{-q T(w)}
$$

and the probability that an application made by an individual paying $w$ will be successful is determined by

$$
s(w)=\frac{1-e^{-q T(w)}}{q T(w)} .
$$

Conditional on a worker having sampled any job offer, the quit probability will be given by the integral of the success probability over the range of desirable offers for the worker who is currently paid $w$ :

$$
\chi(w)=\int_{w}^{\bar{w}} s(x) d F(x) .
$$

Given the new definitions for the probabilistic terms in the model, let us turn our attention to the determination of the optimising behaviour of firms and individuals. The Bellman equation for the value of employment $E(w)$ for a worker in a firm paying $w$ at the beginning of a period is given as follows:

$$
\begin{aligned}
E(w)=\max _{\sigma \in[0,1]}\left\{-c(\sigma)+w+\beta(1-\delta) E(w)+\beta \delta J_{u}\right. \\
\left.+\quad \sigma \int_{w}^{\bar{w}}(x-w+\beta(1-\delta)(E(x)-E(w))) s(x) d F(x)\right\}
\end{aligned}
$$


where $J_{u}$ is the value of unemployment for an individual and satisfies $J_{u}=E(b)$.

Using the envelope theorem this expression can be differentiated with respect to $w$ :

$$
E^{\prime}(w)=\frac{1-\beta(1-\delta) \sigma(w) \chi(w)}{1-\beta(1-\delta)(1-\sigma(w) \chi(w))} .
$$

This confirms that the employment value increases with $w$ and individuals choose to apply to jobs paying more than their current wage.

The optimal choice of the search effort will satisfy the following first order condition:

$$
c^{\prime}(\sigma)=\int_{w}^{\bar{w}}(x-w+\beta(1-\delta)(E(x)-E(w))) s(x) d F(x),
$$

which shows that no search efforts would be incurred at the top end of the wage distribution, since no better offers exist. The conditions imposed on $c(\sigma)$ imply that some search effort will be always exerted and there will be a positive probability of sampling an offer, though never with complete certainty. The optimal search effort determination can be represented through a differential equation:

$$
c^{\prime \prime}(\sigma(w)) \sigma^{\prime}(w)=-\left(1+\beta(1-\delta) E^{\prime}(w)\right) \chi(w),
$$

with boundary condition $\sigma(\bar{w})=0$. Substituting the value of $E^{\prime}(w)$ into this expression it is possible to represent the optimal search decision as a function of the transition probability $\chi(w)$ :

$$
c^{\prime \prime}(\sigma(w)) \sigma^{\prime}(w)=-\left(1+\frac{\beta^{2}(1-\delta)^{2} \sigma(w) \chi(w)}{1-\beta(1-\delta)(1-\sigma(w) \chi(w))}\right) \chi(w) .
$$

The job creation process is very similar to that in the model without search efforts. The firms need to account for the impact that a higher offered wage will have not only on their per period profits and on application and quit decisions, but also on the probability that the worker will exert any effort to find better job offers. Thus, the zero profit condition will state:

$$
\gamma=\frac{1-e^{-q T(w)}}{1-\beta e^{-q T(w)}} \frac{1-w}{1-\beta(1-\delta)(1-\sigma(w) \chi(w))} .
$$

Additionally, the balance in the stock of individuals earning less than or equal to a given wage $w$, namely $u+(1-u) G(w)$, needs to be constant in a steady state equilibrium. This condition is imposed by ensuring that the flows into this stock are exactly compensated by the corresponding outflows:

$$
\delta(1-u)(1-G(w))=(1-\delta) T(w) \chi(w)
$$


where $T(w)$ is defined by equation (17) and $\chi(w)$ by equation (18). As before, the inflow is determined by the measure of individuals earning more than $w$ who loose their jobs and move into unemployment. The expression for the outflow requires certain modifications because sampling of offers is not uniformly distributed over the distribution of unemployed and wage earners below $w$. Thus, the outflow is determined by the product of the measure of individuals $T(w)$ in the stock of interest who sample an offer, times the probability this offer will lie above $w$ and they will be accepted $\chi(w)$. The term $1-\delta$ determines the proportion of those who move that manage to keep their job (prevent exogenous job destruction).

\subsection{Solution of the endogenous search model}

Equations (17), (18), (19), (20) and (21) determine the behaviour of five functions $T(w)$, $F(w), G(w), \chi(w)$ and $\sigma(w)$. Three additional values are unknown, namely $q, u$ and $\bar{w}$. Boundary conditions for this problem are provided by the requirement that $\sigma(\bar{w})=G(b)=$ $F(b)=0, F(\bar{w})=G(\bar{w})=0$ and $T(b)=u \sigma(b)$.

A possible approach to solving this problem involves fixing a given search pattern $\tilde{\sigma}$ for each possible quantile of the wage offer distribution, i.e. for every value in the closed interval $[0,1]$. For example, if $G(w)$ is the proportion of jobs paying less than a given amount $w$, we can specify a search intensity that satisfies $\tilde{\sigma}(G)=\sigma\left(w^{-1}(G)\right)$. Expressing behavior in terms of position in the distribution allows considerable simplification of the exposition.

For example, it is possible to redefine the steady state balance condition in the distribution of earners in terms of $G$ :

$$
\delta(1-u)(1-G)=(1-\delta) \tilde{T}(G) \tilde{\chi}(G),
$$

where $\tilde{\chi}(G)=\int_{G}^{1} \frac{1-\exp (-q \tilde{T}(x))}{q \tilde{T}(x)} d \tilde{F}(x), \tilde{T}(G)=u \tilde{\sigma}(0)+(1-u) \int_{0}^{G} \tilde{\sigma}(\tau) d \tau$ and I follow the convention that every function $\tilde{z}(G)$ satisfies $\tilde{z}(G(w))=z(w)$.

Using the balance condition and the definition of $\tilde{\chi}(G)$ we can state:

$$
\frac{d \tilde{F}(G)}{d G}=\frac{\delta(1-u)}{1-\delta} \frac{\tilde{T}(G)+\tilde{\sigma}(G)(1-G)(1-u)}{\tilde{T}(G)(1-\exp (-q \tilde{T}(G)))} .
$$

This expression is difficult to integrate (also numerically) in order to express the distribution of offers as a function as the position in the distribution of wages. This is because the right hand side term in the expression above (call it $M(G \mid q, u,\{\tilde{\sigma}(x)\})$ for simplicity ${ }^{18}$ )

\footnotetext{
${ }^{18}$ This indicates that $\tilde{F}(G)$ depends on the unknown values for inverse tightness $q$, unemployment $u$, the position of the distribution $G$ and the infinite sequence $\tilde{\sigma}(x)$ of sampling probabilities for every given point in the distribution.
} 
is a function of both $G$ and $T(G)$, which consists of an integral of $\tilde{\sigma}(x)$ terms.

For a given $\tilde{\sigma}(G)$ search behaviour pattern defined for all $G \in[0,1]$, and particular values $u$ and $q$, this differential equation defines a relationship between the distribution of wages across employed individuals and the distribution of wage offers.

$$
F(G)=\int_{0}^{G} M(x \mid u, q,\{\tilde{\sigma}\}) d x .
$$

Given the boundary conditions for $F$ and $G$, it must be also true that the solution satisfies:

$$
1=\int_{0}^{1} M(x \mid u, q,\{\tilde{\sigma}\}) d x .
$$

This equation is the endogenous search model equivalent to (11), and simply defines a relationship between the two unknown values involved, $u$ and $q$, given a particular sequence $\{\tilde{\sigma}\} .{ }^{19}$ It is possible to see that steady-state dynamics must imply a negative relationship between vacancies and unemployment rates, and therefore the association between $q$ and $u$ will be positive.

Expressing the job creation or zero profit condition in terms of $G$ :

$$
\gamma=\frac{1-\exp \left[-q\left(\tilde{\sigma}(0) u+(1-u) \int_{0}^{G} \tilde{\sigma}(\Gamma) d \Gamma\right)\right]}{1-\beta \exp \left[-q\left(\tilde{\sigma}(0) u+(1-u) \int_{0}^{G} \tilde{\sigma}(\Gamma) d \Gamma\right)\right]} \times \frac{1-w(G)}{1-\beta(1-\delta)(1-\tilde{\sigma}(G) \tilde{\chi}(G))}
$$

This allows the derivation of the wage rate associated with each position in the wage distribution. By evaluating this expression at $G=0$, it is possible to obtain the typical job creation condition that produces a positive relationship between number of vacancies and unemployment.

$$
\gamma=\frac{1-\exp [-q(\tilde{\sigma}(0) u)]}{1-\beta \exp [-q(\tilde{\sigma}(0) u)]} \times \frac{1-b}{1-\beta \frac{u-\delta}{u}} .
$$

This equation, together with the dynamics equation, determines the equilibrium unemployment and vacancy rates. Given these values, it is possible to solve for the maximum wage using:

$$
\gamma=\frac{1-\exp \left[-q\left(\tilde{\sigma}(0) u+(1-u) \int_{0}^{1} \tilde{\sigma}(\Gamma) d \Gamma\right)\right]}{1-\beta \exp \left[-q\left(\tilde{\sigma}(0) u+(1-u) \int_{0}^{1} \tilde{\sigma}(\Gamma) d \Gamma\right)\right]} \frac{1-\bar{w}}{1-\beta(1-\delta)} .
$$

This allows inversion of the implicit function $w(G)$, which is defined in equation (23), and hence calculation of the distribution function in its support $[b, \bar{w}]$. This result is conditional

\footnotetext{
${ }^{19}$ Notice that the integrand term is increasing in $q$ and decreasing in $u$. Implicit differentiation shows then that $q$ and $u$ must be positively associated to balance the integrand for each possible value of $G$.
} 
on a given distribution of search behaviour $\tilde{\sigma}(G)=\sigma(w(G))$. For the derived wage and offer distributions, unemployment and vacancy rates, the assumed search behaviour may not be optimal. Differential equation (19) completely defines the optimal search behaviour given $\chi(w)$ and the boundary condition $\sigma(\bar{w})=0$. One potential approach to solving the problem is to solve by repeatedly iterating the process of (1) finding the equilibrium characteristics of the labour market for a given search pattern and then (2) finding the optimal search behaviour associated with these characteristics.

1. Assume a search distribution $\tilde{\sigma}_{0}(G)$ for $G \in[0,1]$.

2. Derive the equilibrium unemployment and vacancy rates $u_{1}$ and $v_{1}=1 / q_{1}$, the equilibrium support $\left[b, \bar{w}_{1}\right]$ and the distribution $G_{1}(w)$. The offer distribution $F_{1}(w)$, the measure of effective contacts below wage $w, T_{1}(w)$, and the conditional mobility probability $\chi_{1}(w)$ can be calculated from $G_{1}(w)$.

3. Find the optimal search behaviour $\sigma_{1}(w)$ associated with the previous equilibrium values. Then it is possible to derive the search efforts conditional on the position in the wage distribution $\tilde{\sigma}_{1}(G)=\sigma_{1}(w(G))$.

4. Repeat until $\tilde{\sigma}_{t}(G)=\tilde{\sigma}_{t+1}(G)$ for all $G \in[0,1]$. In that case $\tilde{\sigma}^{*}(G)=\tilde{\sigma}_{t}(G)$ and $u^{*}=u_{t}, q^{*}=q_{t}, \bar{w}^{*}=\bar{w}_{t}$ and $G^{*}(w)=G_{t}(w)$ for all $w \in\left[b, \bar{w}^{*}\right]$.

It is possible to provide an intuitive explanation for why an equilibrium will exist in the labour market with endogenous search efforts. A steady-state wage posting and search equilibrium can be completely characterised by a set of functions $\{\sigma(w), F(w), G(w)\}$, the equilibrium support $\mathcal{W}$, which is the interval $[b, \bar{w}]$, an unemployment rate $u$ and a value for the inverse of the market tightness $q$ such that the above stated equations hold.

The iterative approach for solving the problem suggests two consecutive transformations. First, a given continuous real valued search function $\tilde{\sigma}(G)$ defined on the compact interval $[0,1]$ is mapped onto a vector $\psi \in \Psi$ of functions $w(G), F(G), \chi(G)$ and values $u, \bar{w}=w(1)$ and $q$. Let us denote this mapping as $\mathcal{T}_{1}: \Omega \rightarrow \Psi$. To derive the successive mapping, consider the differential search equation and the associated boundary condition of no search at $w=\bar{w}$. This maps the vector $\psi$ onto a new function $\tilde{\sigma}(G)$ that belongs to $\Omega, \mathcal{T}_{2}: \Psi \rightarrow \Omega$. A full equilibrium in this model is characterised by a fixed point of the compound transformation $\mathcal{T}=\mathcal{T}_{1} \mathcal{T}_{2}$ that is defined by:

$$
\tilde{\sigma}^{\prime}=\mathcal{T} \tilde{\sigma}
$$

and $\psi=T_{1} \tilde{\sigma}$. A fixed point $\hat{\sigma}$ must satisfy $\tilde{\sigma}=\mathcal{T} \tilde{\sigma}$. 
The natural procedure for showing the existence of an equilibrium or fixed point in this type of environment is to use an extension of Brouwer's fixed point theorem, to the context of bounded continuous functions. ${ }^{20}$ This extension is known as the 'Schauder fixed point' theorem and it states that the transformation $\mathcal{T}=\mathcal{T}_{1} \mathcal{T}_{2}$ has a fixed point when: ${ }^{21}$

1. The domain $X$ of $\tilde{\sigma}$ is a bounded subset of $\Re$. This is true by the definition of the distribution function, with values in the closed interval $X=[0,1]$.

2. Given $C(X)$ as the space of bounded continuous functions on $X$, equipped with the sup norm, $\Omega \subset C(X)$ is nonempty, closed, bounded and convex.

3. The mapping $\mathcal{T}: \Omega \rightarrow \Omega$, where $\tilde{\sigma}^{\prime}=\mathcal{T} \tilde{\sigma}$, is continuous.

4. The family $\mathcal{T}(\Omega)$ is equicontinuous.

The proof of the general theorem is omitted, as well as the detailed proof that the above stated conditions are met by the model considered here. Intuitively, this involves finding bounds for the vacancy rate and the maximum wage offered in equilibrium. Given the productivity normalisation to one, wages offered in equilibrium will lie between $b$ and some value which is always smaller than productivity, for otherwise the vacancy would not have been created. $q$ will be positive and finite given the fact that $b<1$ and $\sigma$ and $G$ are probabilities. The concept of equicontinuity specifies that every transformation must be uniformly continuous and this continuity must also be uniform for all functions in the $\Omega$ space. This step involves the analysis of each one of the two transformations in $\mathcal{T}$.

The existence of a fixed point does not guarantee its uniqueness. With endogenous search efforts, it would be possible to find multiple equilibria with different associated levels of search and wage dispersion. Additionally, this fixed point result does not generally imply that repeated iteration will ever converge. ${ }^{22}$

\footnotetext{
${ }^{20}$ The solution to our problem is not a single value or a finite vector but a function $\tilde{\sigma}(G)$, which is defined on the infinite number points between 0 and 1 .

${ }^{21}$ See Stokey and Lucas (1989) for a general description of fixed point theorems and their applications to economics in recursive problems.

${ }^{22} \mathcal{T}$ being a contraction mapping would be a sufficient, but not necessary condition for convergence and uniqueness.
} 


\section{Empirical implications of the micro-founded match- ing model}

Empirical work on search and matching is seriously constrained by the impossibility of observing the distribution of offers in a labour market. Researchers need to infer this distribution from the information on the wages received by existing workers. One approach to solving this problem is to use the distribution of wages received by individuals who have moved from unemployment into jobs. ${ }^{23}$ In the more typical model with aggregate matching technology, perfect substitutability of employed and unemployed workers in matching and constant returns to scale, it is possible to form a sample analogue of the market offer distribution $F(w)$ by weighting each firm's wage by the relative number of workers hired by that firm directly from non-employment.

The identification relies on the assumption that unemployed individuals, as they are willing to accept any offer higher than $b^{24}$ move into jobs which are supposed to reflect the offer distribution. This ignores the fact that better paying offers will tend to receive more applications and will make application success less likely. If this assumption is not correct, unemployed individuals who sample worse offers will be more likely to move into employment, and those who sample better ones will stand a lower chance of success because of the stronger competition they face from individuals who are currently employed.

Under the micro-founded urn-ball matching technology (which preserves the substitutability and constant returns properties), there is still a sample selection problem for the unemployed, because they don't move uniformly into the jobs offered at one time period in the economy. The transition is weighted by the application success probability of the job sampled, which depends on the number of potential competitors amongst the existing employed workers.

Thus, the estimated cumulative distribution function of earned wages among movers from unemployment will be:

$$
\hat{F}(w)=\int_{b}^{w} \frac{s(x)}{\int_{b}^{\bar{w}} s(t) d F(t)} d F(x) \neq F(w) .
$$

The estimated distribution $\hat{F}(w)$ will tend to put too much weight at the lower part of the equilibrium support, and will be stochastically dominated by the true wage offer distribution. Mathematically, this can stated as:

$$
\Delta(w)=\hat{F}(w)-F(w)=\int_{b}^{w}\left(\frac{s(x)}{\int_{b}^{\bar{w}} s(t) d F(t)}-1\right) d F(x) \geq 0, \forall w \in \mathcal{W} .
$$

\footnotetext{
${ }^{23}$ As explained in Mortensen (1999,2002) and Christensen et al (2001).

${ }^{24}$ Which in equilibrium implies the whole offer distribution.
} 
To show this, notice that $\Delta(b)=0$ and $\Delta(\bar{w})=0 . \Delta(w)$ reaches a maximum at the wage level $\tilde{w}$ that satisfies $s(\tilde{w})=\int_{b}^{\bar{w}} s(t) d F(t)$. This is an interior point of the distribution support. For any $w<\tilde{w}(w>\tilde{w}), \Delta(w)$ is strictly increasing (decreasing) because the application success rate $s(w)$ is strictly decreasing in wages. Thus, $\Delta(w)$ remains positive whenever $w$ stays away from the maximum and minimum wage levels and the stochastic dominance property holds.

Thus, empirical analysis based on an aggregate matching process could wrongly lead us to believe that there are a high number of relatively low wage offers in the labour market. This would be due to the observation of unemployed individuals being proportionally more likely to move into these jobs, due to lower competition from the currently-employed to get into them. This erroneous conclusion is also likely to affect estimates of 'search cost' related parameters because it would be possible to infer a high cost elasticity from data showing unemployed individuals to move faster into jobs than the employed into better jobs after controlling for differences in the pool of desirable wages. This effect is also likely to be important when testing alternative hypotheses of wage determination, i.e. wage posting versus bargaining, etc.

In a model with an aggregate matching technology, the arrival rate of contacts only depends on the relative measures of searching agents on both sides of the market and the associated search intensities. Once a contact is made, there is a strictly bilateral relationship. Within a model in which firms post wages, it is the worker's decision whether to accept the offer or keep searching. Hence, the chance of finding a desirable match from a worker's point of view is:

$$
\pi_{a g}(w)=\sigma(w) \lambda(1-F(w))=\sigma(w) \lambda \int_{w}^{\bar{w}} d F(x),
$$

that is, the product of the probability of sampling an offer in a given period, the homogeneous contact rate $\lambda$ (which depends only on the market tightness) and the probability that the sampled offer is better than the current position. It is interesting to compare this probability with that implied by the micro-founded model:

$$
\pi_{m i c}(w)=\sigma(w) \int_{w}^{\bar{w}} s(x) d F(x) .
$$

Without direct information about the wages offered in a representative sample of job openings, it is impossible to distinguish between these two models. This would be the case in a typical panel data set of individuals. From such data, one can estimate the conditional probability of moving to a job paying $w^{\prime}$ or more for an individual initially earning $w$ or unemployed $(b)$. This probability is given by $\pi_{a g}\left(w^{\prime} \mid w\right)=\sigma(w) \lambda \int_{w^{\prime}}^{\bar{w}} d F(x)$ in the aggregate model; and by $\pi_{m i c}\left(w^{\prime} \mid w\right)=\sigma(w) \int_{w^{\prime}}^{\bar{w}} s(x) d F(x)$ according to my model. This transition data 
does not allow to distinguish between $F^{\prime}(w)$ (the density of offers) and $s(w) F^{\prime}(w)$ (the real density distorted by the application success probability).

A few possible avenues for empirical investigation are open. One involves finding direct data on vacancies that can help estimate $F(w)$ directly. Once this is possible, search intensity $\sigma(w)$ can be subsequently identified and lessons can be learnt about the matching process and the costs involved in job search. It is less likely that information can be obtained from reliable sources about either search efforts or rejection rates $1-s(w)$. The last possibility is to use the actual distribution of wages $G(w)$ and impose the model structure (i.e. the relationship between $F$ and $G$ in equation (22)). The micro-founded model nests the aggregate-matching model in that it does not assume a constant matching rate to jobs sampled by the individuals. Therefore, the hypothesis that would be tested would be $s(w)=s$ for all $w \in \mathcal{W}$.

Assuming the model presented in this paper is a correct description of the matching process, its properties can be used to identify search efforts up to scale. For example, notice that

$$
\frac{\pi_{m i c}\left(w^{\prime} \mid w\right)}{\pi_{m i c}\left(w^{\prime} \mid b\right)}=\frac{\sigma(w)}{\sigma(b)}
$$

for any $w \in \mathcal{W}$. Notice this holds for any $w^{\prime}$ which is larger than $w$, so this provides the intuition for a test about the validity of the general assumption that the current position does not affect opportunities of upward mobility relative to individuals at different levels of the wage distribution. Rejection of this hypothesis could possibly suggest that employers do not choose randomly between applicants and tend to prefer those who had initially higher wages or were simply employed, as opposed to unemployed, even if their skills are observationally equivalent.

\section{Concluding remarks}

This paper has provided micro-foundations for the matching frictions that are at the very heart of endogenous wage and technology dispersion. The main novelty has been to consider such micro-foundations in a highly dynamic environment with on-the-job search. Unlike models where aggregate matching functions are used, the employment probability is not only determined by the relative measures of searching agents on both sides of the market, but also by the distributions of offers and wages across jobs. This has important implications for the way the wage offer distribution can be estimated and imposes restrictions on inferences that can be made from job-worker flows.

By introducing job-specific human capital investments by employers, the basic model gains in terms of producing more realistic, positively skewed wage and capital distributions. 
A more complex version of the model with endogenous search efforts has also been developed. Even though closed form solutions do not exist, it has been shown how a relatively simple iterative numerical model can be used to solve a model in which job search decisions interact with job creation and wage posting decisions as well as labour market flows dynamics. Testable predictions could be examined with the use of matched firm-worker panel data that contains information on search intensity. In particular, it would be possible to test the hypothesis that aggregate matching is an empirically valid simplification of the process bringing workers and jobs together.

Developing micro-foundations for the matching process in the labour market (as it could be done for other types of market), is a hugely promising research area. The urn-ball matching mechanism that has been presented is extremely simple and may not be the most appropriate choice in practice. The formal structure of the model could probably be extended to account (numerically) for more complicated matching processes as long as the steady-state dynamics can be stated in terms of the relative position in the distribution.

We still know very little about the likely impacts of technological changes or policy interventions on improving the efficiency of the matching process. Research findings in this area will be valuable in helping to evaluate how new technologies such as the internet can reduce transaction costs and similar frictions, increase the volume of transactions and shape the distribution of prices.

\section{References}

[1] Acemoglu, D. and Shimer, R. (2000). "Wage and Technology Dispersion", Review of Economic Studies, 67, pp. 585-608.

[2] Anderson, P. and Burgess, S. (2000). "Empirical Matching Functions: Estimation and Interpretation using State-Level Data", Review of Economics and Statistics, 81(1), pp. 93-102.

[3] Bontemps, C., Robin, J.-M. and van den Berg, G. (1997). "Equilibrium Search with Productivity Dispersion: Theory and Estimation", presented at the 1997 Meeting of the Society for Economic Dynamics, Oxford.

[4] Burdett, K. and K. Judd (1983). "Equilibrium Price Dispersion", Econometrica, 51, pp. 955-970.

[5] Burdett, K. and D.T. Mortensen (1989). "Wage Differentials, Employer Size and Unemployment", International Economic Review, 39, pp. 257-274. 
[6] Christensen, B., Lentz, R., Mortensen, Neumann, D. and Werwatz, A. (2001). "On the Job Search and the Wage Distribution", Northwestern Working Paper.

[7] Diamond, P. (1971). "A Model of Price Adjustement", Journal of Economic Theory, 3, pp. 156-168.

[8] Doms, M.; T. Dunn and K. Troske (1997). "Workers, Wages and Technology", Quarterly Journal of Economics, 112, pp. 253-290.

[9] Fallick, B. and C. Fleischman (2001). "The Importance of Employer-to-Employer Flows in the US Labor Market", mimeo.

[10] Galt, V. (2001). "Are Workers Wedded to Their Jobs? Not Likely", Toronto and Globe Mail, August 30.

[11] Gosling, A., Machin, S. and Meghir, C. (2000). "The Changing Distribution of Male Wages in the UK", Review of Economic Studies, 67 (4), pp. 635-666.

[12] Holzer, H., Katz, L. and Krueger, A. (1991). "Job Queues and Wages", Quarterly Journal of Economics, 106, pp. 739-768.

[13] Juhn, C., Murphy, K. and Pierce, B. (1993). "Wage Inequality and the Rise in Returns to Skill", Journal of Political Economy, 101, pp. 410-442.

[14] Katz, L. and Autor, D. (1999). "Changes in the Wage Structure and Earnings Inequality", in Ashenfelter, O. and Card, D. (eds). Handbook of Labor Economics, Volume 3, pp. 1463-1555.

[15] Lang, K. (1991). "Persistent Wage Dispersion and Involuntary Unemployment", Quarterly Journal of Economics, 106, 181-202.

[16] Montgomery, J. (1991). "Equilibrium Wage Dispersion and Interindustry Wage Differentials", Quarterly Journal of Economics, 106, pp. 163-179.

[17] Mortensen, D. (1990). "Equilibrium Wage Distributions; A Synthesis", in Hartog, J., Ridder, G. and Theeuwes, J. (eds.), Panel Data and Labor Market Studies, Amsterdam: North Holland.

[18] Mortensen, D. (1998). "Equilibrium Unemployment with Wage Posting: BurdettMortensen Meet Pissarides", working paper, Centre for Labour Market and Social Research (CLS), Aarhus, Denmark, WP98 014. 
[19] Mortensen, D. (1999). "Modeling Matched Job-Worker Flows", mimeo.

[20] Mortensen, D. (2002). "How Are (Danish) Wages Determined?", mimeo.

[21] Mortensen, D. and Pissarides, C. (1994). "Job Creation and Job Destruction in the Theory of Unemployment", Review of Economic Studies, 61, pp. 397-415.

[22] Mortensen, D. and Pissarides, C. (1999). "New Developments in Models of Search in the Labor Market", in Ashenfelter, O. and Card, D. (eds.) Handbook of Labor Economics, Vol. 3, North Holland.

[23] Murphy, K. and Welch, F. (1992). "The Structure of Wages", Quarterly Journal of Economics, 107, pp. 285-326.

[24] Peters, M. (1991). "Ex Ante Price Offers in Matching Games Non-Steady States", Econometrica, 59, pp. 1425-1454.

[25] Petrongolo, B. and Pissarides, C. (2000). "Looking into the Black Box: A Survey of the Matching Function", discussion paper, Centre for Economic Performance (CEP), DP0470. London School of Economics.

[26] Pissarides, C. (1990). Equilibrium Unemployment Theory. Oxford: Basil Blackwell.

[27] Pissarides, C. (1994). "On-the-Job Search", Review of Economic Studies, 61, pp. 457476.

[28] Stigler, G.J. (1961). "The Economics of Information", Journal of Political Economy, 3, 213- 226.

[29] Stokey, N. and Lucas, R. (1989). Recursive Methods in Economic Dynamics, Cambridge, MA: Harvard University Press.

[30] Van den Berg, G. (1999). "Empirical Inference with Equilibrium Search Models of the Labor Market", Economic Journal, 109, F283-F307. 


\section{IZA Discussion Papers}

\begin{tabular}{|c|c|c|c|c|}
\hline No. & Author(s) & Title & Area & Date \\
\hline 608 & G. Saint-Paul & $\begin{array}{l}\text { Economic Aspects of Human Cloning and } \\
\text { Reprogenetics }\end{array}$ & 3 & $10 / 02$ \\
\hline 609 & G. Saint-Paul & Cognitive Ability and Paternalism & 3 & $10 / 02$ \\
\hline 610 & A. Heitmueller & $\begin{array}{l}\text { Unemployment Benefits, Risk Aversion, and } \\
\text { Migration Incentives }\end{array}$ & 4 & $10 / 02$ \\
\hline 611 & G. Saint-Paul & $\begin{array}{l}\text { Some Thoughts on Macroeconomic Fluctuations } \\
\text { and the Timing of Labor Market Reform }\end{array}$ & 3 & $10 / 02$ \\
\hline 612 & $\begin{array}{l}\text { J. J. Dolado } \\
\text { M. Jansen } \\
\text { J. F. Jimeno }\end{array}$ & $\begin{array}{l}\text { A Matching Model of Crowding-Out and On-the- } \\
\text { Job Search (with an Application to Spain) }\end{array}$ & 2 & $10 / 02$ \\
\hline 613 & $\begin{array}{l}\text { P. Kuhn } \\
\text { M. Skuterud }\end{array}$ & $\begin{array}{l}\text { Internet Job Search and Unemployment } \\
\text { Durations }\end{array}$ & 5 & $10 / 02$ \\
\hline 614 & M. Pannenberg & $\begin{array}{l}\text { Long-Term Effects of Unpaid Overtime: } \\
\text { Evidence for West Germany }\end{array}$ & 1 & $10 / 02$ \\
\hline 615 & W. Koeniger & $\begin{array}{l}\text { The Dynamics of Market Insurance, Insurable } \\
\text { Assets, and Wealth Accumulation }\end{array}$ & 3 & $10 / 02$ \\
\hline 616 & $\begin{array}{l}\text { R. Hujer } \\
\text { U. Blien } \\
\text { M. Caliendo } \\
\text { C. Zeiss }\end{array}$ & $\begin{array}{l}\text { Macroeconometric Evaluation of Active Labour } \\
\text { Market Policies in Germany - A Dynamic Panel } \\
\text { Approach Using Regional Data }\end{array}$ & 6 & $10 / 02$ \\
\hline 617 & $\begin{array}{l}\text { L. Magee } \\
\text { M. R. Veall }\end{array}$ & $\begin{array}{l}\text { Allocating Awards Across Noncomparable } \\
\text { Categories }\end{array}$ & 1 & $10 / 02$ \\
\hline 618 & $\begin{array}{l}\text { A. L. Booth } \\
\text { M. Francesconi } \\
\text { G. Zoega }\end{array}$ & $\begin{array}{l}\text { Oligopsony, Institutions and the Efficiency of } \\
\text { General Training }\end{array}$ & 6 & $10 / 02$ \\
\hline 619 & $\begin{array}{l}\text { H. Antecol } \\
\text { D. A. Cobb-Clark }\end{array}$ & $\begin{array}{l}\text { The Changing Nature of Employment-Related } \\
\text { Sexual Harassment: Evidence from the U.S. } \\
\text { Federal Government (1978-1994) }\end{array}$ & 5 & $10 / 02$ \\
\hline 620 & D. A. Cobb-Clark & $\begin{array}{l}\text { Public Policy and the Labor Market Adjustment } \\
\text { of New Immigrants to Australia }\end{array}$ & 1 & $10 / 02$ \\
\hline 621 & G. Saint-Paul & On Market Forces and Human Evolution & 5 & $11 / 02$ \\
\hline 622 & $\begin{array}{l}\text { J. Hassler } \\
\text { J. V. Rodriguez Mora }\end{array}$ & Should UI Benefits Really Fall Over Time? & 3 & $11 / 02$ \\
\hline 623 & $\begin{array}{l}\text { A. R. Cardoso } \\
\text { P. Ferreira }\end{array}$ & $\begin{array}{l}\text { The Dynamics of Job Creation and Destruction } \\
\text { for University Graduates: Why a Rising } \\
\text { Unemployment Rate Can Be Misleading }\end{array}$ & 1 & $11 / 02$ \\
\hline 624 & $\begin{array}{l}\text { J. Wagner } \\
\text { R. Sternberg }\end{array}$ & $\begin{array}{l}\text { Personal and Regional Determinants of } \\
\text { Entrepreneurial Activities: Empirical Evidence } \\
\text { from the REM Germany }\end{array}$ & 1 & $11 / 02$ \\
\hline 625 & F. Galindo-Rueda & $\begin{array}{l}\text { Endogenous Wage and Capital Dispersion, On- } \\
\text { the-Job Search and the Matching Technology }\end{array}$ & 3 & $11 / 02$ \\
\hline
\end{tabular}

An updated list of IZA Discussion Papers is available on the center's homepage www.iza.org. 